2013

\title{
Capital Structure Deviation and Speed of Adjustment
}

\author{
Tarun Mukherjee \\ University of New Orleans \\ Wei Wang \\ Cleveland State University, w.wang24@csuohio.edu
}

Follow this and additional works at: https://engagedscholarship.csuohio.edu/bus_facpub

Part of the Finance and Financial Management Commons

How does access to this work benefit you? Let us know!

\section{Publisher's Statement}

This is the accepted version of the following article: Mukherjee, T., Wang, W. (2013). Capital

Structure Deviation and Speed of Adjustment. The Financial Review, Eastern Finance

Association, 48, pp.597-615., which has been published in final form at 10.2139/ssrn.1927698

\section{Original Published Citation}

Mukherjee, T., Wang, W. (2013). Capital Structure Deviation and Speed of Adjustment. The Financial Review, Eastern Finance Association, 48, pp.597-615.

This Article is brought to you for free and open access by the Monte Ahuja College of Business at EngagedScholarship@CSU. It has been accepted for inclusion in Business Faculty Publications by an authorized administrator of EngagedScholarship@CSU. For more information, please contact library.es@csuohio.edu. 


\title{
Capital Structure Deviation and Speed of Adjustment
}

\author{
Tarun Mukherjee* \\ University of New Orleans \\ Wei Wang \\ University of New Orleans
}

\begin{abstract}
As a firm deviates from its target leverage from above (below), the bankruptcy costs (foregone tax savings) rise at an increasing rate while the tax savings (reduced bankruptcy costs) rise at a decreasing rate, generating a stronger incentive for rebalancing capital structure. This phenomenon renders the speed of adjustment (SOA) an increasing function of the deviation. Employing a bootstrapping-based estimation strategy that averts well-known estimation biases, we find U.S. firms exhibit a positive SOA sensitivity to leverage deviation. Also, the SOA sensitivity is greater for overlevered than underlevered firms.
\end{abstract}

Keywords: capital structure, speed of adjustment, adjustment costs, heterogeneity, bootstrapping

JEL Classification: G32

*Corresponding author: University of New Orleans, 2000 Lakeshore Dr, New Orleans, LA 70148; Phone: (504) 280-7146; Fax: (504) 280-6397; E-mail: tmukherj@uno.edu.

Our paper has greatly benefited from the valuable comments and suggestions of Ivo Welch, Peter Iliev, Bonnie Van Ness (the editor), and two anonymous reviewers. We also thank discussants and seminar participants at the 2012 Southwestern Finance Association conference- "Best Paper in Corporate Finance" (New Orleans), the 2012 Midwest Finance Association 2012 Conference (New Orleans), the 2012 Financial Management Association Asian conference (Phuket, Thailand), and the 2012 Financial Management Association conference (Atlanta) for their comments. All errors are ours. 


\section{Introduction}

According to the tradeoff theory, capital structure decisions involve considerations of a tradeoff primarily between debt-incurred tax shield and bankruptcy costs. A firm's optimal (target) capital structure is where the marginal tax shield from leverage equals its marginal bankruptcy costs, and a deviation from the target represents a loss in firm value. In the presence of costs associated with security issuance and repurchase, however, a firm will act to eliminate the deviation if and when the net benefit of adjustment is greater than the costs (e.g., Fischer, Heinkel and Zechner, 1989; Strebulaev, 2007). Thus, adjustment costs could hold back a firm from rebalancing its capital structure, as evidenced by the preponderance of empirical evidence showing on average a slow adjustment process. ${ }^{1}$ Since potential for cross-firm differences in adjustment costs and benefits exists, heterogeneous SOAs are likely results.

A small but growing strand of the capital structure literature examines the effect of adjustment costs on a firm's SOA. They typically instrument adjustment costs with certain firm characteristics like firm size and report a negative relation between adjustment costs and SOA. For example, Jalilvand and Harris (1984) show that larger firms adjust faster than small ones. Byoun (2008) finds overlevered (underlevered) firms rebalance more actively when they are faced with a financial surplus (deficit). A potential explanation, albeit not explicitly made in his paper due to its focus, is that the financial surplus saves the firm a special trip to the capital market and hence lowers the costs of reducing leverage. Faulkender, Flannery, Hankins and Smith (2012) (hereafter referred to as FFHS 2012) extend this probe to argue that large cash flow realizations will lower leverage adjustment costs and induce faster adjustments. Empirically, they find a positive relation between the magnitude of cash flows and SOA. Lockhart (2010) shows that access to credit lines is associated with notably faster SOA, again due to the lower adjustment costs. Oztekin and Flannery (2012) conduct a cross-country study to confirm the link between SOAs and proxies of adjustment costs.

Our paper differs from the literature discussed above in that it emphasizes the linkage between adjustment benefit and adjustment speed. In particular, we posit that a firm's SOA positively depends on the deviation from its target leverage. The rationale rests on the discrepant rates at which the tax shield and bankruptcy costs change as the leverage deviation increases. Abstracting from progressive tax rates, the expected tax shield is a concave function of the use of debt, increasing at a decelerating rate which eventually turns negative, as the likelihood of using the full extent of the tax shield offered by debt diminishes with leverage. In contrast, the

\footnotetext{
${ }^{1}$ The speed of adjustment (SOA) estimates range from 7\% to 10\% in Fama and French (2002) to 36\% in Flannery and Rangan (2006), corresponding to half-lives of leverage deviation from 1.6 years to 9.6 years. In the same vein, Leary and Roberts (2005) conclude that firms undo leverage shocks in a slow and intermittent fashion via equity and debt issuance activities. The partial adjustment phenomenon echoes the survey results of Graham and Harvey (2001) that most firms claim to have capital structure targets, but achieving the target is not always of prime urgency, and both are consistent with the tradeoff theory.
} 
bankruptcy costs are generally known as increasing at an increasing rate as more debt is loaded. As a result, the firm value is a concave function of debt, as illustrated in the famous figure 1 in Myers (1984). Above (below) the target leverage, the bankruptcy costs rise (decline) at a faster (slower) speed than the tax benefits as the leverage further deviates, and hence, the benefit from adjusting the capital structure, or put it another way, the cost of not adjusting, increases with deviation, giving the manager greater incentives to move the leverage toward the target.

In the presence of adjustment costs, rebalancing occurs only if the benefit of adjustment exceeds the costs. Thus, the shape of adjustment costs relative to the shape of adjustment benefit would determine when and how fast a firm adjusts. Leary and Roberts (2005) show that adjustment costs consist of a fixed element plus a weakly convex variable element. The presence of a fixed cost implies that the firm might not correct small deviations from the target as adjustment costs are likely to be higher than the benefit derived from rebalancing. A likely implication of a weakly convex variable cost is that the adjustment-cost curve is flatter than the curve of adjustment benefit. $^{2}$ This implication makes intuitive sense, because otherwise adjustment costs that start with a fixed level and rise faster than the adjustment benefit would render rebalancing a value-destroying measure. ${ }^{3}$ Insofar as the adjustment costs increase at a slower rate than the costs of not adjusting, the net benefit from rebalancing widens with the size of deviation from the target capital structure. Consequently, the greater the deviation from target, the bigger the incentive to adjust and the higher the speed at which a firm adjusts.

We confirm the existence of such a positive SOA sensitivity to leverage deviation in a large sample of U.S. industrial firms during 1966-2008. The estimated sensitivity is statistically and economically greater than zero, regardless of leverage measures and target leverage measures. The result is also robust to the Welch (2004) leverage adjustment model. In other words, the SOA is robustly and positively related to the distance from the target leverage. On average a one-standard-deviation increase in book leverage deviation is associated with an increase in the SOA by 0.104 , which is large compared to the average SOA across all firms of about 0.12 .

The deviation dependency of SOA, when coupled with the asymmetric capital structure behavior (e.g., FFHS 2012), suggests that the SOA sensitivity to leverage deviation would depend on whether a firm's current capital structure is below or above

\footnotetext{
2 The literature suggests marginal bankruptcy costs are greater than marginal adjustment costs. For instance, Hennessy and Whited (2007) estimate that marginal equity floatation costs are 5.0\% (10.7\%) and marginal bankruptcy costs equal to $8.4 \%(15.1 \%)$ of capital for large (small) firms. In addition, although Andrade and Kaplan (1998) and Altinkilic and Hansen (2000) do not find conclusive evidence of bankruptcy costs having greater curvature than adjustment costs, they do not find evidence to the contrary either.

${ }^{3}$ It is highly conceivable that beyond some point above the target, the costs of adjustment exceed the benefit to be derived from adjustment. For example, an extremely overlevered firm might decide to go bankrupt rather than rebalance its capital structure as external capital becomes prohibitively costly. We will account for this situation later.
} 
the target. To be more specific, as the cost of not adjusting increases at an increasing rate on the right-hand side of the target, the SOA for an overlevered firm is expected to rise faster than that of an underlevered firm. We present evidence in support of this hypothesis.

We are the first to specifically examine cross-sectional heterogeneity in capital structure adjustment in terms of its relation with the leverage deviation. This relation per se is vital because the loss in firm value due to suboptimal capital structure is, by definition, intimately tied to the extent of deviation. This paper also features an innovative, bootstrapping-based method to estimate SOA. As discussed in Iliev and Welch (2011), existing estimators of the partial adjustment model fail to account for the boundedness of leverage ratio, which gives rise to mechanical mean reversion of leverage (Chen and Zhao, 2007; Chang and Dasgupta, 2009). To address this issue, we compare and interpret the SOA estimate in the real data against those in bootstrapped placebo samples, in which leverage ratios evolve by randomly drawn debt and equity changes and deliberate capital structure adjustments are missing. This way the difference between the real estimate and the placebo estimate depicts the effect of active adjustments on capital structure, net of estimation biases.

\section{Method and data}

In this section, we describe in detail our model that incorporates the potential heterogeneity in SOA, identify target leverage, and specify the bootstrapped-based estimation strategy. At the end, we discuss the data we use.

\subsection{Capital structure dynamic specification}

The canonical capital structure adjustment model holds that a firm that starts with a leverage ratio that is deviated from its target leverage will move to eliminate part or all of the deviation:

$$
L_{i, t}-L_{i, t-1}=\lambda\left(L_{i, t}^{*}-L_{i, t-1}\right)+\varepsilon_{i, t},
$$

where $L_{i, t-1}$ and $L_{i, t}$ are the beginning and ending leverage of firm $i$ in period $t$, and $L_{i, t}^{*}$ is the target leverage. Hence $L_{i, t}^{*}-L_{i, t-1}$ and $L_{i, t}-L_{i, t-1}$ represent the starting leverage deviation and the adjustment in leverage in period $t$. The coefficient of leverage deviation, $\lambda$, represents the fraction of the starting deviation that is eliminated during the period, and is the SOA.

Our main hypothesis is that the SOA is positively related to the starting deviation because the benefit of adjustment increases faster than costs of adjustment as the deviation expands in most of the allowable range of leverage ratio. This is found in the prior literature on adjustment costs and bankruptcy costs as discussed in the introduction. However, the fact that firms in some cases choose to go bankrupt rather than rebalance indicates that adjustment costs may become prohibitively high as the 
leverage ratio gets very close to 1 . Therefore, we allow for heterogeneity in SOA along the starting deviation by expressing $\lambda$ as a linear function of the deviation as well as an indicator of extremely high leverage in our baseline regression model:

$$
L_{i, t}-L_{i, t-1}=\left(\lambda_{0}+\lambda_{1}\left|L_{i, t}^{*}-L_{i, t-1}\right|+\gamma I_{H}\right)\left(L_{i, t}^{*}-L_{i, t-1}\right)+\varepsilon_{i, t},
$$

where $\lambda_{0}$ and $\lambda_{1}$ are constants for all firms and years, and represent the common element of SOA and the SOA sensitivity to leverage deviation, respectively. $I_{H}$ is an indicator equal to 1 if the beginning leverage, $L_{i, t-1}$, is greater than 0.9 , and we expect its coefficient, $\gamma$, to be negative. While this indicator variable controls for the extreme high leverage case, we are mainly interested in how the SOA varies with leverage deviation, that is, $\lambda_{1}$. If the SOA increases, as we expect, with the deviation, then $\lambda_{1}$ is significantly positive. If both $\lambda_{1}$ and $\gamma$ are zero, then Equation (2) degenerates to the standard partial adjustment Equation (1).

Following the literature, including Kayhan and Titman (2007), Lockhart (2010), and FFHS (2012), we adopt a two-step procedure to estimate Equations (1) and (2). In the first step, we estimate the target leverage, $L_{i, t}^{*}$, as the predicted value of leverage ratio in the following capital structure determination model:

$$
L_{i, t}=\beta X_{i, t-1}+\varepsilon_{i, t},
$$

where, $X_{i, t-1}$ represents a set of time-varying firm and industry characteristics that are predetermined. The set of characteristics are not always the same across studies (e.g., Flannery and Rangan, 2006; Lemmon, Roberts and Zender, 2008; Frank and Goyal, 2009). In our baseline estimation, we mimic Lemmon, Roberts and Zender (2008) and consider the following determinants: log of assets, market-to-book ratio, profitability, asset tangibility, cash flow volatility, a dummy variable indicating whether the firm pays a dividend or not, and the industry median leverage ratio. These variables are defined in Table 1. Considering the definition of leverage ratio bounds it between 0 and 1, we estimate Equation (3) as a double-censored Tobit model.

The second step is to substitute the target from Equation (3) into the adjustment Equations (1) and (2) and estimate the SOA, the SOA sensitivity to leverage deviation, and other parameters. We use a bootstrapping-based method as discussed in the next section.

\subsection{Bootstrapping-based estimation}

The literature provides at least four estimators for the capital structure adjustment model, including the pooled ordinary least squares (OLS) (e.g., Kayhan and Titman, 2007), the fixed effects estimator (Flannery and Rangan, 2006), the Blundell-Bond system Generalized Method of Moments (GMM) estimator (e.g., Lemmon, Roberts and Zender, 2008), and the long-difference instrument variable estimator (Huang and Ritter, 2009). Out of these the system GMM estimator appears to perform the best (Flannery and Hankins, 2013). However, they do not address the mechanical 
Table 1

Variable definitions

\begin{tabular}{|c|c|}
\hline Variable & Definition \\
\hline Assets (at) & Total assets (at) \\
\hline Debt $(d e b t)$ & The sum of long-term debt (dltt) and short-term debt (dlc) \\
\hline Liabilities (lt) & Total liabilities $(l t)$ \\
\hline Book equity (beq) & $\begin{array}{l}\text { Book equity, defined as } \max (\operatorname{seq}, 0.01 * \text { debt, } 0.001 * \text { assets }) \text { when } s e q \text { is } \\
\text { available, where } \operatorname{seq} \text { is the stockholders' equity }\end{array}$ \\
\hline Market equity (meq) & $\begin{array}{l}\text { Market equity, defined as seq-ceq }+c s h o^{*} \operatorname{prcc} f \text {, where } s e q \text { is stockholders' } \\
\text { equity, } c e q \text { is common equity, } c s h o \text { is the number of shared outstanding, and } \\
\text { prcc } f \text { is the stock price at the end of the fiscal year }\end{array}$ \\
\hline $\begin{array}{l}\text { Market debt-to-capital } \\
\text { ratio }\end{array}$ & Baseline leverage measure, defined as debt/(debt $+m e q)$ \\
\hline $\begin{array}{l}\text { Book debt-to-capital } \\
\quad \text { ratio }\end{array}$ & Alternative leverage measure, defined as debt/(debt $+b e q)$ \\
\hline Firm age & Firm age \\
\hline Log assets & $\begin{array}{l}\text { The logarithm of }(1+a t) \text {, where assets are in million dollars, adjusted to } 2000 \\
\text { levels using the gross domestic product deflator }\end{array}$ \\
\hline Market-to-book ratio & $\begin{array}{l}\text { Market value of total assets divided by book assets, defined as }(m e q+d e b t+ \\
p s t k c-t x d i t c) / a t \text {, where } p s t k c \text { is convertible preferred stock, and txditc is } \\
\text { deferred taxes and investment tax credit. pstkc and txditc are set to zero if } \\
\text { missing }\end{array}$ \\
\hline Profitability & Defined as operating income before depreciation $(o i b d p) /$ assets $(a t)$ \\
\hline Asset tangibility & Defined as net property, plant and equipment (ppent)/assets (at) \\
\hline Cash flow volatility & $\begin{array}{l}\text { Standard deviation of historic profitability (profit), requiring at least three } \\
\text { years of data }\end{array}$ \\
\hline $\begin{array}{l}\text { Dividend payer } \\
\text { indicator }\end{array}$ & Indicator variable, equal to 1 if dividend is paid in the fiscal year \\
\hline $\begin{array}{l}\text { Industry median } \\
\text { leverage }\end{array}$ & $\begin{array}{l}\text { The median leverage ratio across all firms in the two-digit SIC industry in a } \\
\text { year }\end{array}$ \\
\hline Stock return $\left(r_{t}\right)$ & Stock return without dividends during the fiscal year \\
\hline $\begin{array}{l}\text { Welch (2004) implied } \\
\text { debt ratio }\left(L_{i, t}^{W}\right)\end{array}$ & $\begin{array}{l}\text { The market debt-to-capital ratio that comes about if a firm issues neither debt } \\
\text { nor equity, defined as } \operatorname{Debt}_{t-1} /\left(\text { Debt }_{t-1}+m e q_{t-1} \cdot\left(1+r_{t}\right)\right)\end{array}$ \\
\hline \multirow[t]{3}{*}{ Leverage target } & $\begin{array}{l}\text { The leverage ratio predicted by firm characteristics and industry median in the } \\
\text { previous year. The prediction model is }\end{array}$ \\
\hline & $L_{i, t}=\beta X_{i, t-1}+\varepsilon_{i, t}$ \\
\hline & $\begin{array}{l}\text { where } X \text { is a vector of firm characteristics (log assets, market-to-book ratio, } \\
\text { profitability, asset tangibility, cash flow volatility, dividend payer indicator) } \\
\text { and industry median leverage. The model is treated as a double-censored Tobit } \\
\text { model with an upper limit of } 1 \text { and a lower limit of } 0 \text {, and estimated in a year- } \\
\text { by-year manner to avoid the look-ahead bias }\end{array}$ \\
\hline
\end{tabular}

mean reversion issue of leverage ratio. ${ }^{4}$ The issue, as discussed in Chen and Zhao (2007), Chang and Dasgupta (2009), and Iliev and Welch (2011), is caused by the

\footnotetext{
${ }^{4}$ Contemporaneous to our paper, Elsas and Florysiak (2011) propose a fractional dependent variable estimator to address this issue. Our method provides an alternative.
} 
boundedness of leverage ratio between zero and one. ${ }^{5}$ The above estimators do not account for this propensity and potentially give exaggerated SOAs.

We propose a bootstrapping-based estimation approach that removes the effect of mechanical mean reversion of leverage ratio. First, we estimate the leverage adjustment models in our real sample using OLS to obtain biased estimates of, among others, the SOA and the SOA sensitivity to leverage deviation. The biases include the bias of the OLS estimator in the dynamic panel model (Hsiao, 2003) as well as that due to mechanical mean reversion of leverage ratio. Then we follow the data-generating process in Iliev and Welch (2011) to create "placebo" samples, in which leverage ratios evolve with randomly drawn debt and equity percent changes, so as to learn what estimates might be obtained under the null hypothesis of no managerial intervention. In the absence of deliberate adjustments, the estimates in these placebo samples reflect only estimation biases. To the extent that our estimates, both in the real data and in the placebo samples, are subject to the same set of biases, their differences give us the unbiased estimates of SOA and SOA sensitivity to leverage deviation. ${ }^{6}$

In practice, for each regression, we bootstrap 250 placebo samples and their estimates constitute the null distribution of parameters in our adjustment models, which makes statistical inferences possible. The bootstrapping procedure is described in the Appendix. The evolution of debt and equity under our placebo datagenerating process is independent of the firm's own characteristics; hence, resulting estimates of SOA and SOA sensitivity are free from any conscious efforts of the firm's manager.

\subsection{Data and variables}

We extract financial data from the annual Compustat database for all but financial (Standard Industrial Classification [SIC] 6000-6999) and utility (SIC 4900-4999) firms listed on NYSE, Amex, and NASDAQ for the 1965-2008 period. The data exclude firm years with missing data for book assets, assets lower than \$1 million in 2000 U.S. dollars, or missing information in both Compustat and CRSP for computing the year-end market equity. We require that each firm in our sample has at least two

\footnotetext{
${ }^{5}$ In particular, Chang and Dasgupta (2009) show via Monte Carlo simulations that even when firms follow random financing, the partial adjustment model will yield a positive SOA, a result that is a mechanical byproduct devoid of any theoretical basis. An intuitive explanation for this outcome is that, the nonlinearity of the leverage ratio makes it more difficult to further raise (lower) a leverage ratio than to lower (raise) it given an already high (low) leverage. Consequently, leverage ratio exhibits a "mechanical" propensity to revert to intermediate levels.

${ }^{6} \mathrm{~A}$ caveat is in order: it is difficult to show analytically that the estimation biases are identical for the real and placebo samples. However, in untabulated results, we show that three existing estimators, that is, pooled OLS, fixed effects, and system GMM, which give widely diverse SOA estimates in the conventional partial adjustment model, yield similar "net" SOA estimates after the placebo SOA is deducted. This is consistent with estimation biases of these estimators being correctly removed.
} 
consecutive years of observations, given our interest in the leverage adjustment. Our data-filtering process follows the typical method in the literature, and the final sample includes 115,299 firm-year observations for 9,314 firms, which, on average, is 12.4 years per firm.

We use both the book and market debt-to-capital ratios to measure financial leverage, the former defined as total debt (short-term and long-term debt) divided by total book capital, that is, the sum of total debt and book equity, and the latter defined as total debt divided by the sum of market equity and debt. To avoid unreasonable leverage ratios, we winsorize the book equity at the bottom as the highest out of the book equity, $1 \%$ of total debt and $0.1 \%$ of total assets. Most firm characteristics, including firm size, market-to-book ratio, profitability, asset tangibility and cash flow volatility, are winsorized at the top and bottom one-percentiles to mitigate the effect of outliers and eradicate errors in the data.

\section{Results}

\subsection{Summary statistics}

Table 2 presents the statistical summary for our sample. Leverage is measured by both the book and market debt-to-capital ratios. The book leverage ratio averages 0.308 with a median of 0.286 and a standard deviation of 0.251 . The market leverage ratio has a lower mean of 0.240 , consistent with the market-to-book ratio being greater than 1 in both mean and median. The estimated target leverage ratios have similar means to the actual debt ratios but smaller variances. Leverage deviation is calculated as the difference between the target leverage and the actual leverage, and its mean and median are close to zero for both book and market debt-to-capital ratios. Industry median leverage is the median leverage ratio across all firms in the same two-digit SIC industry in the year, and its lag value is used together with firm characteristics to predict target leverage.

An average firm in our sample has $\$ 1,963$ million in assets. Its market-to-book ratio is 1.54, its operating income before depreciation accounts for $10.3 \%$ of its assets (profitability), $31.6 \%$ of assets are tangible, and its cash flow volatility is $9.3 \%$. Fortysix percent of the firms pay dividends. These statistics are very similar to those found in other studies in this area (e.g., Lemmon, Roberts and Zender, 2008).

\subsection{Homogeneous SOA estimates using bootstrapping-based method}

Using the bootstrapping approach described above, we first estimate the SOA based on the assumption that it is the same for all the firms and all years. In other words, we estimate Equation (2) in both the real sample, and in the 250 bootstrapped placebo samples and then compare the estimated real coefficient, $\lambda$, against the mean placebo coefficient. The purpose is to provide a basic SOA estimate from which heterogeneous SOA will be developed later. The results are reported in Table 3. 
Table 2

\begin{tabular}{|c|c|c|c|c|c|}
\hline \multicolumn{6}{|l|}{ Statistic summary } \\
\hline \multicolumn{6}{|c|}{$\begin{array}{l}\text { Our final sample includes } 115,299 \text { firm-year observations during } 1966-2008 \text { for } 9,314 \text { nonfinancial, } \\
\text { nonutility firms listed on NYSE, Amex and NASDAQ exchanges. We require a firm has assets of at } \\
\text { least } 1 \text { million unadjusted U.S. dollars and at least two consecutive years of financial data available from } \\
\text { Compustat. Nonadjacent fiscal years of a same GVKEY are treated as separate firms. This table provides } \\
\text { summary statistics for leverage measures, target leverage ratios, initial deviation from targets, historic } \\
\text { industry median leverage, and firm characteristics. Leverage is measured by book and market debt-to- } \\
\text { capital ratios. Leverage targets are estimated in a regression based on firm and industry characteristics as } \\
\text { described in Table } 1 \text {. Historic industry median leverage is the historic median leverage ratio of firms in the } \\
\text { same two-digit SIC industry. Firm characteristics include total assets in year } 2000 \text { dollar, adjusted using } \\
\text { the gross domestic product deflator, firm age, market-to-book ratio, profitability measured as operating } \\
\text { income before depreciation and amortization divided by assets, asset tangibility as fixed assets divided by } \\
\text { total assets, cash flow volatility measured as the standard deviation of profitability, and whether the firm } \\
\text { pays dividends in the fiscal year (dividend payer indicator). }\end{array}$} \\
\hline Variable & Mean & Median & Std Dev & 10th pctl & 90th petl \\
\hline \multicolumn{6}{|l|}{ Leverage } \\
\hline Book debt-to-capital ratio & 0.308 & 0.286 & 0.251 & 0 & 0.649 \\
\hline Market debt-to-capital ratio & 0.240 & 0.181 & 0.229 & 0 & 0.587 \\
\hline Target book leverage & 0.292 & 0.297 & 0.141 & 0.095 & 0.470 \\
\hline Target market leverage & 0.232 & 0.231 & 0.145 & 0.027 & 0.413 \\
\hline Deviation from target book leverage & 0.011 & -0.015 & 0.216 & -0.232 & 0.288 \\
\hline Deviation from target market leverage & 0.001 & -0.016 & 0.178 & -0.194 & 0.238 \\
\hline Industry median book leverage & 0.274 & 0.281 & 0.138 & 0.090 & 0.450 \\
\hline Industry median market leverage & 0.193 & 0.176 & 0.140 & 0.030 & 0.379 \\
\hline \multicolumn{6}{|l|}{ Firm characteristics } \\
\hline Assets $(\$ \mathrm{~m})$ & $1,963.4$ & 147.7 & 11684.5 & 15.7 & $2,788.2$ \\
\hline Market-to-book ratio & 1.54 & 1.06 & 1.45 & 0.54 & 3.01 \\
\hline Profitability & 0.103 & 0.131 & 0.209 & -0.036 & 0.248 \\
\hline Asset tangibility & 0.316 & 0.266 & 0.225 & 0.061 & 0.667 \\
\hline Cash flow volatility & 0.093 & 0.059 & 0.135 & 0.021 & 0.183 \\
\hline Dividend payer indicator & 0.463 & 0 & 0.499 & 0 & 1 \\
\hline
\end{tabular}

The SOA estimate in the real data for both book and market leverage are in column 2, and the means and standard deviations of SOA across the placebo samples are in columns 3 and 4. For book leverage, the real sample estimate is 0.164 , consistent with existing OLS estimates in the literature. The SOA estimates in the bootstrapped placebo samples have a mean of 0.045 and a small standard deviation of 0.001 . The average placebo SOA is significantly greater than zero, justifying the necessity of removing estimation biases using the bootstrapping-based approach. Note that the spurious SOA in the placebo samples where deliberate targeting is missing reflects the combined effect of the bias of OLS estimator in our dynamic panel context and the mechanical mean reversion of leverage ratio. Given that the OLS estimate of SOA is known to be downwardly biased (e.g., Huang and Ritter, 2009), the spurious SOA caused by the mechanical mean reversion should be greater than 0.045 . 
Table 3

\section{Homogeneous speed of adjustment (SOA) toward target leverage}

This table shows model estimates in both the real data and the bootstrapped placebo data of the homogeneous SOA model below:

$$
L_{i, t}-L_{i, t-1}=\lambda\left(L_{i, t}^{*}-L_{i, t-1}\right)+\varepsilon_{i, t},
$$

where $L_{i, t}$ is measured by the market and book debt-to-capital ratios, $L_{i, t}$ is the regression-based target leverage, and the coefficient, $\lambda$, measures the average capital structure SOA. The placebo samples are generated by bootstrapping random debt and equity issuance to update leverage and deliberate managerial interventions are missing. The estimated coefficients in the real data are in column 2. The mean and standard deviation of the coefficient in the 250 placebo samples are in columns 3 and 4, respectively. Column 5 displays the difference between the real coefficient and the mean null coefficient, which is our estimate of SOA after removing the effect of mechanical mean reversion of leverage ratio. Column 6 shows the implied half-life of leverage deviation given the estimated SOA.

\begin{tabular}{|c|c|c|c|c|c|}
\hline \multirow[b]{2}{*}{ Leverage } & \multicolumn{4}{|c|}{$\lambda$} & \multirow{2}{*}{$\begin{array}{c}\text { Half-life } \\
\text { (years) }\end{array}$} \\
\hline & Real & Placebo & $\sigma_{\text {Placebo }}$ & Real - placebo & \\
\hline Book leverage & 0.164 & $0.045^{* *} *$ & 0.001 & $0.120^{* *}$ & 5.5 \\
\hline Market leverage & 0.195 & $0.054 * *$ & 0.001 & $0.141 * *$ & 4.6 \\
\hline (1) & (2) & (3) & (4) & (5) & (6) \\
\hline
\end{tabular}

**, * indicate statistical significance at the 0.01 and 0.05 level, respectively, evaluated against the placebo distribution of SOA.

The difference between real and placebo estimates (column 5), which shows the true SOA free of estimation biases, is 0.120 for book leverage, falling, not surprisingly, into the lower end of the range in prior estimates in the literature $(0.07-0.36)$. This finding says firms on average eliminate $12 \%$ of their leverage deviations each year, corresponding to a half-life of 5.5 years. $^{7}$ The market debt-to-capital ratio exhibits similar results. The placebo SOA estimates average 0.054 and the "net" SOA is 0.141 , corresponding to a half-life of 4.6 years.

\subsection{Heterogeneous SOAs that depend on leverage deviation}

\subsubsection{Initial deviation and subsequent adjustment of leverage}

Figure 1 depicts a graphical look at the relation between the starting deviation from target leverage and the subsequent change in capital structure. For either leverage measure, we partition the sample into equal-sized quintiles based on the leverage deviation at the beginning of a fiscal year and then compute the change in the average leverage ratio for each quintile in the year. Two lines are drawn to show the leverage change in the original real sample and in the 250 placebo samples, respectively. Firms increase their leverage when underlevered (small deviation

\footnotetext{
${ }^{7}$ The half-life is calculated as $\ln (0.5) / \ln (1-\mathrm{SOA})$.
} 

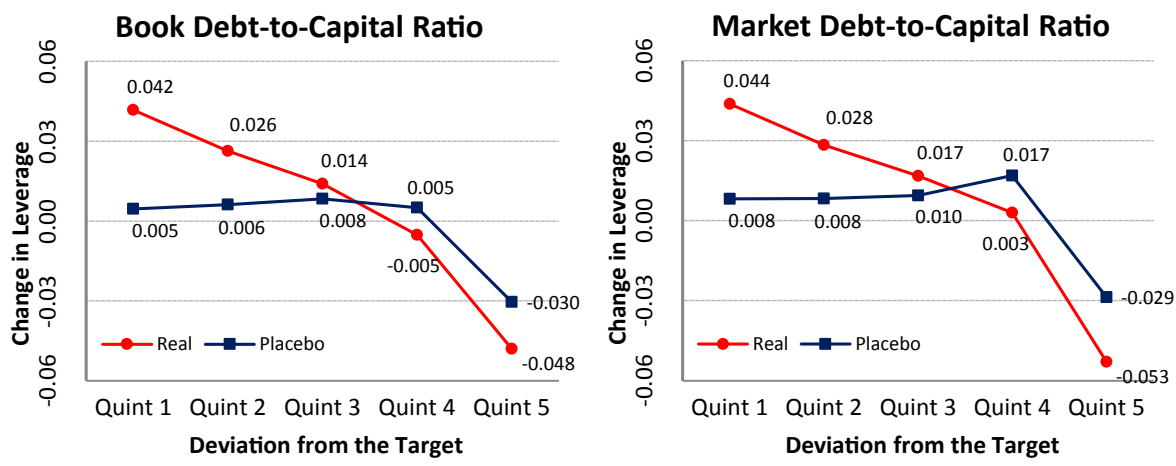

Figure 1

Deviation and subsequent change in leverage

The figure shows the average initial leverage deviation from the target and the change in leverage in the subsequent fiscal year of U.S. industrial firms during 1966-2008. Leverage is measured by book and market debt-to-capital ratios, and the target is estimated as a linear function of firm characteristics and industry median leverage in the previous year.

in Quintile 1 and Quintile 2) and decrease it when overlevered (large deviation in Quintile 4 and Quintile 5), and the adjustment is greater as leverage deviation is greater. This adjustment appears real because bootstrapped firms exhibit a similar but much weaker pattern. The figure, however, fails to give us the comparison of the adjustment speeds to which now we turn.

\subsubsection{Does SOA depend on leverage deviation?}

Our alternative hypothesis is that a firm's SOA in a given year is positively related to its starting deviation from the target, because larger deviation normally means larger benefit of rebalancing the leverage. To test it, we estimate Equation (3) and report the coefficients, $\lambda_{0}, \lambda_{1}$, and $\gamma$, in Table 4 . If $\lambda_{1}$ is significantly greater than zero, then the null hypothesis of homogeneous SOA is rejected, with the conclusion being that SOA is positively related to starting leverage deviation.

The estimates in the real sample, the mean and standard deviations of estimates in the 250 placebo samples, the difference between the real estimates and the mean placebo estimates, and the implied economic effect are reported in columns 3 through 7 , respectively. We are most interested in $\lambda_{1}$, which measures the SOA sensitivity to leverage deviation. In the real data, $\lambda_{0}$ is merely 0.032 (compared to the homogenous SOA estimate of 0.164 ) while $\lambda_{1}$ is 0.498 for book leverage, implying that the book leverage SOA is largely variable and determined mainly by the leverage deviation. The placebo $\lambda_{1}$ is 0.019 , not significantly different from zero, implying that it does not depend on leverage deviation in the placebo samples. The difference 
Table 4

\section{Speed of adjustment (SOA) and leverage deviation}

This table shows model estimates in both the real data and the bootstrapped placebo data of the heterogeneous SOA model below:

$$
L_{i, t}=L_{i, t-1}+\left(\lambda_{0}+\lambda_{1}\left|L_{i, t}^{*}-L_{i, t-1}\right|+\gamma I_{H}\right)\left(L_{i, t}^{*}-L_{i, t-1}\right)+\varepsilon_{i, t},
$$

where $L_{i, t}$ is measured by the market and book debt-to-capital ratios, $L_{i, t}^{*}$ is the regression-based target leverage, and $\mathrm{I}_{\mathrm{H}}$ is a dummy variable that is equal to 1 if is greater than 0.9 . The placebo samples are generated by bootstrapping random debt and equity issuance to update leverage without allowing for deliberate managerial interventions. The estimated coefficients in the real data are in column 3 . The means and standard deviations of the coefficients in the 250 placebo samples are in columns 4 and 5 , respectively. Column 6 displays the difference between the real coefficients and the mean placebo coefficients. Column 7 shows the implied difference in leverage adjustment between two firms whose initial leverage deviations are one-standard-deviation away from each other. The standard deviation of leverage deviation is 0.216 for book debt-to-capital ratio and 0.178 for market debt-to-capital ratio.

\begin{tabular}{lcccccc}
\hline Leverage & Parameter & Real & Placebo & $\sigma_{\text {Placebo }}$ & Real - placebo & Implied effect \\
\hline Book leverage & $\lambda_{0}$ & 0.032 & $0.033^{* *}$ & 0.011 & -0.001 & \\
& $\lambda_{1}$ & 0.498 & 0.019 & 0.011 & $0.479^{* *}$ & 0.104 \\
Market leverage & $\gamma$ & -0.414 & -0.002 & 0.008 & $-0.412^{* *}$ & \\
& $\lambda_{0}$ & 0.155 & $0.031^{*}$ & 0.016 & $0.124^{* *}$ & \\
& $\lambda_{1}$ & 0.201 & $0.036^{*}$ & 0.018 & $0.165^{* *}$ & 0.029 \\
$(1)$ & $\gamma$ & -0.377 & $-0.088^{* *}$ & 0.014 & $-0.289^{* *}$ & \\
& $(2)$ & $(3)$ & $(4)$ & $(5)$ & $(6)$ & $(7)$ \\
\hline
\end{tabular}

**, * indicate statistical significance at the 0.01 and 0.05 level, respectively, evaluated against the placebo distributions.

between the two estimates gives us the unbiased estimate of SOA sensitivity to leverage deviation, 0.479 , which is statistically significant at the $1 \%$ level. If firm $\mathrm{X}$ 's leverage departure ${ }^{8}$ is $10 \%$ higher than that of firm Y, then X's SOA would be faster than Y's by about 0.048 . This difference is large compared to the average SOA estimate of 0.120 .

To better gauge the economic significance of our results, we calculate the difference in the SOA between two firms of which the initial leverage departures differ by one standard deviation, as shown in column 7 . The "net" $\lambda_{1}$ is 0.479 , and the standard deviation of the initial leverage departure from target is 0.216 (Table 2), and their product is 0.104 , or $10.4 \%$. Now assume two firms, A and B, both of which have the target book debt-to-capital ratio of $30 \%$, and firm $\mathrm{A}$ is overlevered with a debt ratio of, say, $40 \%$, while firm B's debt ratio is one-standard-deviation higher, that is, 0.616. Then firm A would shed $4.7 \%(=-0.001+0.479 * 10 \%)$ of the starting departure in the first year and firm B would trim down its leverage ratio by $15 \%$ $(=-0.001+0.479 * 0.316)$. The implied SOAs allow us to make two more direct

\footnotetext{
${ }^{8}$ Hereafter we use "leverage departure" in place of "leverage deviation," where necessary, to avoid such expressions as "the standard deviation of leverage deviation."
} 
comparisons. First, firm A lowers its leverage ratio by $4.7 \% * 10 \%=0.5$ percentage point, while firm B lowers its ratio by $15 \% * 31.6 \%=4.7$ percentage points. Second, the half-life of the leverage deviation is about 20 years for firm A in contrast to merely 5.9 years for firm B. ${ }^{9}$

Employing market leverage yields somewhat different results, but the main finding that SOA is positively related to starting leverage deviation remains. The "net" $\lambda_{0}$ is 0.124 , representing a statistically significant fixed component of SOA. The "net" $\lambda_{1}$ is 0.165 , implying a difference in leverage adjustment of 2.9 percentage points between two firms whose leverage departures are one-standard-deviation $(0.178)$ away from each other. The third parameter, $\gamma$, has significantly negative estimates for both book and market leverage, consistent with firms with extremely high leverage finding adjustment costs prohibitively high and opting to go under.

These findings are consistent with our dynamic tradeoff theory-based hypothesis that, as leverage deviation gets larger, the slope of the bankruptcy costs gets steeper relative to that of the tax shield, entailing greater benefits from rebalancing. This finding also permits us to draw an inference regarding the shape of adjustment costs. The positive dependency of SOA on starting deviation is possible only when the marginal adjustment costs increase at a slower rate than the marginal bankruptcy costs. These findings point to a fixed plus weakly convex variable adjustment-cost regime, consistent with Leary and Roberts (2005). ${ }^{10}$

\subsection{Asymmetric SOA sensitivity to leverage deviation}

Myers (1984) postulates that firm managers are likely to be more concerned about excessive leverage than inadequate leverage for at least two reasons. First, the opportunity cost of the lost tax shield stemming from underuse of leverage might be offset (at least partially) by benefits from reserve debt capacity that might be used to exploit future opportunities. Second, the firm's ultimate cost of being overlevered is the total loss of value of its shares, while the ultimate cost of being underlevered is the opportunity cost associated with the lost tax shield. Thus, the managers' incentive to adjust in an overlevered situation is likely to be higher than when the firm is in an underlevered situation, implying a faster SOA when the firm is overlevered. Asymmetry in SOA per se can be viewed as a type of heterogeneity that firms with the identical extent of leverage deviation, yet of different signs,

\footnotetext{
${ }^{9}$ Because we assume the SOA is constant within any year but changes year to year, it is a step function of the leverage deviation from target, and there is not a convenient equation to solve for the half-life. Instead, we find the half-life case by case, taking into account the varying SOA.

${ }^{10}$ We conduct a series of robustness tests to confirm that our findings hold. The robustness tests involve employing (1) alternative leverage measures, (2) alternative leverage target measures, (3) alternative bootstrapping strategies, (4) the Welch (2004) adjustment model, (5) alternative cutoffs for high leverage indicator, and we obtain the positive SOA sensitivity to leverage deviation under every scenario. The results are available at request.
} 
Table 5

Asymmetric speed of adjustment (SOA)

This table shows estimates in both the real data and the bootstrapped placebo data of the capital structure adjustment model that allows for asymmetric SOA as below:

$$
L_{i, t}=L_{i, t-1}+\lambda_{U L}\left(L_{i, t}^{*}-L_{i, t-1}\right) \cdot I_{L_{i, t}^{*}>L_{i, t-1}}+\lambda_{O L}\left(L_{i, t}^{*}-L_{i, t-1}\right) \cdot I_{L_{i, t}^{*} \leq L_{i, t-1}}+\varepsilon_{i, t},
$$

where $L_{i, t}$ is measured by book and market debt-to-capital ratios, and $L_{i, t}^{*}$ is the target leverage based on a vector of firm and industry characteristics. Indicator variable $I_{L_{i, t}^{*}}>L_{i, t-1}$ is equal to 1 if $L_{i, t}^{*}>L_{i, t-1}$; indicator variable $I_{L_{i, t}^{*} \leq L_{i, t-1}}$ is equal to 1 if $L_{i, t}^{*} \leq L_{i, t-1}$. The estimated coefficients in the real data are in column 4 . The means and standard deviations of the coefficients in the 250 null samples are in columns 5 and 6, respectively. Column 7 displays the difference between the real coefficients and the mean placebo coefficients. Column 8 presents the implied half-lives of leverage deviation in the real data and the placebo data as well as their difference.

\begin{tabular}{llcccccc}
\hline Leverage & Subsample & Parameter & Real & Placebo & $\sigma_{\text {Placebo }}$ & Real - placebo & Half-life (years) \\
\hline Book leverage & Underlevered & $\lambda_{U L}$ & 0.157 & $0.057^{* *}$ & 0.002 & $0.100^{* *}$ & 6.6 \\
& Overlevered & $\lambda_{O L}$ & 0.177 & $0.021^{* *}$ & 0.001 & $0.156^{* *}$ & 4.1 \\
& Difference & & & & & $-0.056^{* *}$ & 2.5 \\
Market leverage & Underlevered & $\lambda_{U L}$ & 0.198 & $0.067^{* *}$ & 0.004 & $0.131^{* *}$ & 4.9 \\
& Overlevered & $\lambda_{O L}$ & 0.215 & $0.038^{* *}$ & 0.001 & $0.177^{* *}$ & 3.6 \\
& Difference & & & & & $-0.046^{* *}$ & 1.4 \\
$(1)$ & $(2)$ & $(3)$ & $(4)$ & $(5)$ & $(6)$ & $(7)$ & $(8)$ \\
\hline
\end{tabular}

**, * indicate statistical significance at the 0.01 and 0.05 level, respectively.

adjust at different rates. Empirically, there is scattered documentation of asymmetric capital structure behavior. For instance, Chen and Zhao (2007) show that financing decisions supporting the targeting theory primarily come from highly levered firms that cut debt. Leary and Roberts (2005) find firms' propensity of rebalancing given a high or lifted leverage is greater than that given a low or reduced leverage. Byoun (2008), Lockhart (2010) and FFHS (2012) provide direct evidence that the SOA is greater for overlevered firms. However, it is not clear whether the evidence holds after eliminating mechanical mean reversion of leverage ratio. We use the following model to estimate the different SOAs in the underlevered and overlevered subsamples:

$$
\begin{aligned}
L_{i, t}= & L_{i, t-1}+\lambda_{U L}\left(L_{i, t}^{*}-L_{i, t-1}\right) \cdot I_{L_{i, t}^{*}>L_{i, t-1}} \\
& +\lambda_{O L}\left(L_{i, t}^{*}-L_{i, t-1}\right) \cdot I_{L_{i, t}^{*} \leq L_{i, t-1}}+\varepsilon_{i, t},
\end{aligned}
$$

where, $I_{L_{i, t}^{*} \leq L_{i, t-1}}$ and $I_{L_{i, t}^{*}>L_{i, t-1}}$ are indicator variables that take on a value of 1 for underlevered and overlevered firms, respectively. If SOA is asymmetric, we expect the overlevered subsample to have higher SOA than the underlevered subsample, that is, $\lambda_{O L}>\lambda_{U L}$. The model is estimated using our bootstrapping-based approach.

Table 5 presents the estimated SOA for underlevered and overlevered firms in the real data, reported in column 4 , as well as the mean and standard deviation of SOA in the 250 bootstrapped placebo samples, in columns 5 and 6 . The real data 
SOA is greater for overlevered firms, and the placebo SOA is statistically positive in both subsamples. Again we are most interested in their difference between the real data estimate and the placebo estimate that reflects the "net" SOA that is free of mechanical mean reversion. This result is reported in column 7. For both book and market leverage, we do find a greater SOA for overlevered firms. For example, SOA is 0.156 for overlevered firms, corresponding to a half-life of 4.1 years, but is only 0.100 for underlevered firms, corresponding to a half-life of 6.6 years. The difference in SOA is economically significant.

The asymmetry in average SOA, coupled with deviation-dependent heterogeneity, suggests yet another asymmetry - the SOA sensitivity to deviation. For a same deviation from target, a firm would employ a greater SOA when the deviation is above rather than below the target. This implies that the SOA increases faster as deviation expands in the overlevered domain. In other words, when a firm further deviates from the target leverage from above, the manager will feel faster accumulating pressure to undo the deviation than when the same deviation occurs from below. The finding of asymmetric SOA sensitivity to leverage deviation would corroborate our earlier findings of the positive association between SOA and starting leverage deviation.

The specification of our asymmetrically heterogeneous SOA model is

$$
\begin{aligned}
L_{i, t}= & L_{i, t-1}+\left(\lambda_{0}+\lambda_{1}^{+}\left|L_{i, t}^{*}-L_{i, t-1}\right|+\gamma I_{H}\right)\left(L_{i, t}^{*}-L_{i, t-1}\right) \cdot I_{L_{i, t}^{*} \leq L_{i, t-1}} \\
& +\left(\lambda_{0}+\lambda_{1}^{-}\left|L_{i, t}^{*}-L_{i, t-1}\right|\right)\left(L_{i, t}^{*}-L_{i, t-1}\right) \cdot I_{L_{i, t}^{*}>L_{i, t-1}}+\varepsilon_{i, t},
\end{aligned}
$$

where $I_{L_{i, t}^{*} \leq L_{i, t-1}}$ and $I_{L_{i, t}^{*}>L_{i, t-1}}$ are indicators for overlevered and underlevered firms, respectively. We use the plus and minus superscripts to differentiate the coefficients for overlevered firms and underlevered firms. The potential asymmetry in SOA sensitivity to leverage deviation would be reflected in the difference between the two sensitivity parameters, that is, $\lambda_{1}^{+}$and $\lambda_{1}^{-}$. Note that in our bootstrapped-based estimation, the true heterogeneity effect involves a comparison between estimated coefficients in the real data and the placebo data, hence examination of asymmetry in SOA sensitivity to leverage deviation can be viewed as a difference-in-difference test.

Estimation results are in Table 6 . The positive relation between SOA and leverage deviation remains in both the overlevered subsample and the underlevered one as the "net" sensitivity estimates, $\lambda_{1}^{+}$and $\lambda_{1}^{-}$, are all significantly positive. For instance, as book leverage is employed, the SOA sensitivity to leverage deviation is 0.523 among overlevered firms and 0.428 among underlevered ones. The comparison between these two sensitivity estimates is shown in the last row of column 7 for either leverage measure as the difference (between overlevered firms and underlevered firms) in difference (between real and placebo estimates). The metric is 0.095 for book leverage, which is statistically significant at the 5\% level. A quick gauge shows that, a one-standard-deviation increase in leverage departure above the target would enhance the SOA by 9.2 percentage points, while the effect of a one-standarddeviation increase in leverage departure below the target is 4.4 percentage points, differing by 4.8 percentage points. We witness weaker but qualitative similar results 
Table 6

Asymmetric speed of adjustment (SOA) sensitivity to leverage deviation

This table shows estimates in both the real data and the bootstrapped placebo data of the heterogeneous SOA model that allows for asymmetric speed of adjustment as below:

$$
\begin{aligned}
L_{i, t}= & L_{i, t-1}+\left(\lambda_{0}^{+}+\lambda_{1}^{+}\left|L_{i, t}^{*}-L_{i, t-1}\right|+\gamma I_{H}\right)\left(L_{i, t}^{*}-L_{i, t-1}\right) \cdot I_{L_{i, t}^{*} \leq L_{i, t-1}} \\
& +\left(\lambda_{0}^{-}+\lambda_{1}^{-}\left|L_{i, t}^{*}-L_{i, t-1}\right|\right)\left(L_{i, t}^{*}-L_{i, t-1}\right) \cdot I_{L_{i, t}^{*}>L_{i, t-1}}+\varepsilon_{i, t},
\end{aligned}
$$

where $L_{i, t}$ is measured by book and market debt-to-capital ratios, and $L_{i, t}^{*}$ is the target leverage based on a vector of firm and industry characteristics. Indicator variable $I_{L_{i, t}^{*}}>L_{i, t-1}$ is equal to 1 if $L_{i, t}^{*}>L_{i, t-1}$; $I_{L_{i, t}^{*} \leq L_{i, t-1}}$ is equal to 1 if $L_{i, t}^{*} \leq L_{i, t-1}$. The estimated coefficients in the real data are in column 3 . The means and standard deviations of the coefficients in the 250 null samples are in columns 4 and 5 , respectively. Column 6 displays the differences between the real coefficients and the mean placebo coefficients. Column 7 presents the implied difference in leverage adjustment between two underlevered (or overlevered) firms whose leverage deviation is one-standard-deviation away from each other, as well as the difference in difference of leverage adjustment between underlevered and overlevered firms. The standard deviation of positive and negative leverage deviations are 0.175 and 0.103 respectively for book leverage, and 0.144 and 0.090 respectively for market leverage.

\begin{tabular}{lcccccc}
\hline Leverage & Parameter & Real & Placebo & $\sigma_{\text {Placebo }}$ & Real - placebo & Implied effect \\
\hline Book leverage & $\lambda_{0}$ & 0.046 & $0.043^{* *}$ & 0.005 & $0.003^{* *}$ & \\
& $\lambda_{1}^{+}$ & 0.530 & 0.007 & 0.008 & $0.523^{* *}$ & 0.092 \\
& $\lambda_{1}^{-}$ & 0.371 & -0.057 & 0.045 & $0.428^{* *}$ & 0.044 \\
& $\gamma$ & -0.478 & -0.002 & 0.009 & $-0.476^{* *}$ & \\
Market leverage & $\lambda_{1}^{+}-\lambda_{1}^{-}$ & 0.159 & 0.064 & 0.042 & $0.095^{*}$ & 0.048 \\
& $\lambda_{0}$ & 0.165 & $0.029^{* *}$ & 0.009 & $0.137^{* *}$ & \\
& $\lambda_{1}^{+}$ & 0.207 & $0.039^{* *}$ & 0.009 & $0.168^{* *}$ & 0.024 \\
& $\lambda_{1}^{-}$ & 0.091 & 0.049 & 0.058 & $0.043^{* *}$ & 0.004 \\
& $\gamma$ & -0.418 & $-0.111^{* *}$ & 0.016 & $-0.307^{* *}$ & \\
& $\lambda_{1}^{+}-\lambda_{1}^{-}$ & 0.116 & -0.009 & 0.059 & $0.125^{*}$ & 0.020 \\
\hline
\end{tabular}

**, * indicate statistical significance at the 0.01 and 0.05 level, respectively.

when market debt-to-capital ratio is the measure of leverage. Therefore, the findings support our hypothesis that overlevered firms exhibit greater sensitivity to increasing deviation from their target capital structure.

\section{Conclusions}

The link between starting leverage deviation and the SOA is vital because the loss in firm value due to suboptimal capital structure is, by definition, intimately tied to the extent of deviation. Based on the cost-benefit analysis of the use of debt, we postulate that the SOA of capital structure is positively associated with the starting leverage deviation. The hypothesis hinges primarily on the difference in rates at which bankruptcy costs and tax shield of debt change as a firm moves away from its target leverage. Without loss of generality, the marginal tax shield is a decreasing function while the marginal bankruptcy cost is an increasing function of the leverage. The net 
benefit of rebalancing (or the loss in firm value due to not rebalancing) expands at an increasing rate as the leverage moves farther away from the target. Consequently, a firm's incentive to rebalance its capital structure increases. This benefit must be balanced against the cost of readjustment. What continues to make the leverage deviation relevant to capital structure rebalancing is that the slope of the net adjustment benefit curve gets steeper relative to the cost of adjustment curve as the leverage deviation increases, providing inducement to the firm to employ a higher SOA.

We examine this hypothesis in a large sample of U.S. industrial firms during 1966-2008 and demonstrate that the SOA is positively related to the distance from the target leverage. Indeed, on average a one-standard-deviation difference in initial leverage departure could lead to a difference of 10.4 percentage points in the SOA, which is very large because the average SOA across all firms is about $12 \%$. The results are robust regardless of leverage measures, target measures, bootstrapping strategies, and leverage adjustment models. We also demonstrate that the adjustment behavior is asymmetric in that a firm exhibits a greater sensitivity to leverage deviations when it is above rather than below its target capital structure.

A useful by-product of this paper is a bootstrapping-based estimation approach to address the mechanical mean reversion of leverage ratio. We bootstrap random debt and equity changes to create placebo samples where managerial interventions are missing, then estimate the leverage adjustment model in the real sample as well as placebo samples, and interpret the real estimate against the distribution of the placebo estimate. The difference between the real estimate and placebo estimate then represents the pure effect of active adjustment of capital structure, net of estimation bias caused by mechanical mean reversion. This approach can be modified to deal with situations requiring similar expositions.

\section{Appendix: Creating placebo samples using bootstrapping}

The placebo jointly models random debt and equity changes. The procedure works as follows:

(1) For each firm year, we draw another random firm year from the sample. This draw is selected without regard to any characteristics of the firm or the draw.

(2) We compute the percent change in equity and the percent change in debt of the random draw.

(3) We use the percent change in debt and the percent change in equity from the draw to compute a random evolution for the original firm's leverage as below:

$$
L_{i, t}=\frac{D_{i, t}}{D_{i, t}+E_{i, t}}=\frac{D_{i, t-1} \cdot\left(1+v_{j, t-1, t}\right)}{D_{i, t-1} \cdot\left(1+v_{j, t-1, t}\right)+E_{i, t-1} \cdot\left(1+\eta_{j, t-1, t}\right)},
$$

where $D_{i, t}, D_{i, t-1}, E_{i, t}, E_{i, t-1}$ are the original firm's debt and equity at time $t-1$, and debt and equity at time $t$, respectively; is the fractional change in equity from $t-1$ to 
$t$, and $v_{j, t-1, t}$ is the fractional change in debt from $t-1$ to $t$, of the random draw firm.

Theoretically, $\eta_{j, t-1, t}$ and $v_{j, t-1, t}$ can be as low as -1 and as high as $\infty$; they are winsorized at -0.8 on the down side and 5 on the up side to avoid frequent extreme moves. To illustrate the data-generating process, let us assume that a sample firm starts out with $\$ 50$ in debt and $\$ 50$ in equity for a leverage ratio of $50 \%$. We select a random firm-year draw. Say that this firm-year draw happens to show an increase in its debt from $\$ 10$ to $\$ 30$ and an increase in its equity from $\$ 40$ to $\$ 60$. Applying the $200 \%$ change in debt and the $50 \%$ change in equity, a random evolution moves the original sample firm from its $50 \%$ leverage ratio to a $\$ 150 /[\$ 150+\$ 75] \approx 66.7 \%$ leverage ratio. Our procedure preserves all the essential characteristics of a bounded ratio. The following year, this firm's $66.7 \%$ leverage ratio is adjusted by another random firm-year draw.

The evolution of debt and equity under this process is independent of the firm's own characteristics. With so few assumptions about how debt and equity evolve, our process is a conservative placebo in the sense that a model of deliberate managerial intervention should find it easy to reject the notion that real-world debt ratios behave just like such placebo evolutions. Any statistic obtained from data sets so simulated should not be attributed to the deliberate actions of managers based on the firm's own characteristics, in particular, leverage deviation.

\section{References}

Altinkilic, O. and R.S. Hansen, 2000. Are there economies of scale in underwriter fees? Evidence of rising external financing costs, Review of Financial Studies 13, 191-218.

Andrade, G. and S.N. Kaplan, 1998. How costly is financial (not economic) distress? Evidence from highly levered transactions that became distressed, Journal of Finance 53, 1443-1493.

Byoun, S., 2008. How and when do firms adjust their capital structures toward targets? Journal of Finance 63, 3069-3096.

Chang, X. and S. Dasgupta, 2009. Target behavior and financing: How conclusive is the evidence? Journal of Finance 64, 1767-1796.

Chen, L. and X. Zhao, 2007. Mechanical mean reversion of leverage ratios, Economic Letters 95, 223-229.

Elsas, R. and D. Florysiak, 2011. Heterogeneity in the speed of adjustment toward target leverage, International Review of Finance 11, 181-212.

Fama, E. and K. French, 2002. Testing tradeoff and pecking order predictions about dividends and debt, Review of Financial Studies 15, 1-33.

Faulkender, M., M.J. Flannery, K.W. Hankins, and J.M. Smith, 2012. Cash flows and leverage adjustments, Journal of Financial Economics 103, 632-646.

Fischer, E., R. Heinkel, and J. Zechner, 1989. Dynamic capital structure choice: Theory and tests, Journal of Finance 44, 19-40.

Flannery, M. and K.W. Hankins, 2013. Estimating dynamic panel models in corporate finance, Journal of Corporate Finance 19, 1-19.

Flannery, M. and K.P. Rangan, 2006. Partial adjustment toward target capital structures, Journal of Financial Economics 79, 469-506.

Frank, M.Z. and V.K. Goyal, 2009. Capital structure decisions: Which factors are reliably important? Financial Management 38, 1-37. 
Graham, J.R. and C.R. Harvey, 2001. The theory and practice of corporate finance: Evidence from the field, Journal of Financial Economics 60, 187-243.

Hennessy, C.A. and T.M. Whited, 2007. How costly is external financing? Evidence from a structural estimation, Journal of Finance 62, 1705-1745.

Hsiao, C., 2003. Analysis of Panel Data (Cambridge University Press, Cambridge, UK).

Huang, R. and J. Ritter, 2009. Testing theories of capital structure and estimating the speed of adjustment, Journal of Financial and Quantitative Analysis 44, 237-271.

Iliev, P. and I. Welch, 2011. Reconciling estimates of the speed of adjustment of leverage ratios. Working paper, UCLA.

Jalivand, A. and R.S. Harris, 1984. Corporate behavior in adjusting to capital structure and dividend targets: An econometric study, Journal of Finance 39, 127-145.

Kayhan, A. and S. Titman, 2007. Firms' histories and their capital structures, Journal of Financial Economics 83, 1-32.

Leary, M.T. and M.R. Roberts, 2005. Do firms rebalance their capital structures? Journal of Finance 60, 2575-2619.

Lemmon, M.L., M.R. Roberts, and J.F. Zender, 2008. Back to the beginning: Persistence and the crosssection of corporate capital structure, Journal of Finance 63, 1575-1608.

Lockhart, G.B., 2010. Adjusting to target capital structure: The effect of credit lines. Working paper, University of Nebraska-Lincoln.

Myers, S.C., 1984. The capital structure puzzle, Journal of Finance 39, 575-592.

Öztekin, Ö. and M.J. Flannery, 2012. Institutional determinants of capital structure adjustment speeds, Journal of Financial Economics 103, 88-112.

Strebulaev, I.A., 2007. Do tests of capital structure theory mean what they say? Journal of Finance 62, 1747-1787.

Welch, I., 2004. Capital structure and stock returns, Journal of Political Economy 112, 106-131. 